\title{
The Role of Information Quality in Healthcare Organizations: A Multi-Disciplinary Literature Review
}

\author{
Geir Inge Hausvik \\ University of Agder, Norway \\ geir.i.hausvik@uia.no
}

\begin{abstract}
The volume of data in healthcare repositories is growing exponentially, giving increased concerns on its organizational implications. The quality of data and information represents a considerable risk for organizations, particularly in healthcare, where consequences of poor quality may be fatal for patients. This research seeks to investigate the role of information quality in organizations, by reviewing multi-disciplinary research literature and provide a framework of the relations between IQ and its organizational implications. Findings suggest that research on information quality has focused on different aspects of organizational impact: organizational performance, process performance, process improvement, and decision-making. However, since the research is fragmented and scarce, this paper suggests a shift in research focus from defining, measuring and improving information quality, to understanding the implications and applications of information quality towards better and safer health services.
\end{abstract}

\section{Introduction}

There is considerable risk related to the massive amount of health data and its corresponding administrative process data registered in dispersed health information systems (HIS). This risk is everincreasing, since the amount of data in healthcare has an exponential growth and has recently been characterized as 'big data' [30]. This risk is related to the impact of poor management and government of information quality (IQ), and is directly related to quality of the health services provided to patients [38], where the consequences of poor IQ for patients are major, even fatal [58]. One of the challenges is the nature of data in the healthcare context; "Medical data are a particular thorny problem: they are copious, complex, hard to verify, and entered by many uncoordinated hands" [32].

IQ is dependent on the quality of raw data in order to execute effective decision-making both at strategic and clinical level of healthcare. One study reported 42 percent of interviewees citing poor data quality in healthcare to be a major barrier in decision-making [21]. The same study reported cumbersome processes in healthcare for requesting information (mostly adhoc), no standards in terms of empirical measures of core processes, lack of understanding of information needs, and labor intensive and time consuming processes of obtaining value from data, often by manually exporting and manipulating data in spreadsheets.

The multi-dimensional concept of IQ is assumed to play an important role in systematic healthcare quality improvement by informing actors when quality improvement initiatives are needed, and by assessing the performance of such initiatives. In their study, Dixon-Woods, McNicol and Martin [19] claim that data collection in designing and planning of healthcare quality improvement projects, including feedback to actors throughout the project, is indispensable. Their study concludes that this is one of the top challenges in improving quality in healthcare, but offers little scientific contributions to how this challenge should be addressed. Within the research stream of Total Quality Management (TQM) and performance, empirical and theoretical research focusing on understanding leading and lagging results, models for understanding impact of decisions throughout the organization, and information system influence, are considered significant opportunities for research [20].

Spanning three decades of research, IQ is unquestionably an important area within the disciplines of Information Systems (IS) and e-Health, where the main focus has been on defining, measuring, and improving IQ [41]. Given the crucial importance of information in healthcare, this leads to a more fundamental question - how is IQ actually impacting healthcare organizations? In order to synthesize the 
existing, yet sparse and diversified research, a framework of how IQ is related to healthcare organizations would be beneficial. This research paper seeks to develop such a research framework by conducting a multi-disciplinary literature review.

The remainder of the paper is organized as follows: In the next section, the concept of IQ and its current limitations are presented, followed by description of the research methodology. Then, findings are presented, followed by a discussion of research gaps and suggestions for future research directions. Finally, conclusions are drawn.

\section{The concept of information quality}

This study recognizes the existence of data and information as two ontologically separated entities. However, existing literature has tended to use both expressions when discussing the same concept. In order to maintain parsimony, this research, like e.g., Neely and Cook [41], uses 'information quality' interchangeably with 'data quality'.

IQ is a multi-dimensional concept, where the most widely adopted definition is "fitness for use" [41]. This definition implies that information considered appropriate for one user, may be insufficient for another, and is thus contingent upon the context of use, where a component of subjectivity influences the perception of usefulness.

Though IQ has been the subject of research since the mid-1980s, consensus is still not reached about the definition of the construct and its attributes [8]. Furthermore, the extant literature gives no precise answers to what constitutes 'good' ('high') or 'bad' ('low') IQ, but rather suggests perception of quality to be dependent upon user needs, roles and agenda [48]. It is even claimed an impossibility to describe, assess or assure IQ in one single model, since the attributes are dependent on the context where information is originated [53]. However, the sets of dimensions presented by Wang and Strong [55] are the most common operationalization of IQ - intrinsic, contextual, representational, and accessible [49]. This includes the intrinsic dimension of IQ implying information to have quality in its own right. Attributes of intrinsic IQ are believability, accuracy, objectivity, and reputation. The contextual dimension highlights IQ to be considered within its context of use, thus supporting the task of information consumers. Attributes of contextual IQ are value-added, relevancy, timeliness, and completeness. The representational dimension relates to how information is formatted and presented to information consumers, and includes the attributes of appropriate amount of information, interpretability, ease of understanding, and consistency and conciseness of representation of information. The final dimension is accessible IQ. This relates to how information is accessed in the information systems, and includes accessibility and access security.

Theoretical frameworks incorporating IQ as part of achieving IS success, such as the Technology acceptance model (TAM) [16] and the DeLone and McLean (D\&M) IS success model [17, 18], have gained widespread acceptance [28]. The (updated) D\&M success model explains how IQ, system quality, and service quality positively impact users' satisfaction of an IS and their intentions to use the IS, leading to 'Net benefits'. Despite its popularity, the model has been criticized on several accounts; first, the model has been criticized for being too technology-oriented, implying that the technological characteristics is determining the overall impact [28]. Second, the model emphasizes the importance of IQ to understand the organizational impact of IS/IT, but fails to specify its role [11]. And third, the application of the model has been reported to mostly deal with individual benefits rather than organizational benefits [27].

There exist several former reviews of IQ research, with different focus. Ge and Helfert [23] divided existing research on IQ into three distinct domains; IQ assessment, IQ Management, and Contextual IQ. Another review presented a taxonomy where fitnessfor-use categories (who, what, how, economic resources, and human safety) were identified by IQ research categories (Governance, Operations, Technology, and Decision-making within context) [41]. The latter study revealed that the major topics of research were related to assessment and monitoring of IQ dimensions, stakeholders' perception of quality, definition of IQ, and how to detect data errors. Interestingly, noneconomic impact of IQ on organizations and processes was only found in 12 of 649 research articles. This finding has later been confirmed by several researchers claiming for limitations in the IQ literature, e.g., of IQ dimensions' relationship to business process improvement and redesign [29, 42, 45], lack of attention to IQ dimensions in decisions related to organizational performance [46, 59], lack of attention to IQ in business process management and process execution, [e.g., 36], and limited descriptions of organizational performance as independent variable in IQ research [7].

\section{Research methodology}

This literature review is underpinned by the philosophical tradition of critical realism (CR). The notion of 'critical' in CR is to be understood as epistemological relativity [39], thus having direct consequences for the methodology chosen (i.e., by 
valuing paradigmatic diversification). The methodology used in this research is primarily based on the work of Okoli [43, 44], where the goal is to identify relevant literature and record the phenomena observed in a wide area of existing research (i.e., theory landscaping). This implies that research on IQ in organizations outside healthcare is also valued, since transferability between contexts might exist. The eightstep guide [44] was used to conduct the literature review, consisting of the following steps: Identify the purpose, Draft protocol, Apply practical screening, Search for literature, Extract data, Appraise quality, Synthesize studies (data analysis), and Write the review.

A protocol of search strategies, inclusion and exclusion criteria, was designed prior to the search process, to ensure consistency in the process and theoretical rigor $[43,44]$. Practical screening (not to be confused with quality appraisal) sets the practical boundaries of the search process. An important factor in critical realism is epistemological relativity, i.e., all viewpoints are equally valid [39]. Thus, no practical screening criteria was employed concerning journal rankings, field of research (multi-disciplinary approach), outlet (journals, conference proceedings, books, practitioner publications, grey literature), research paradigms (positivistic, interpretive, conceptual etc.), or dates (no date limitations). Only two practical screening criteria were used; language, with only English articles being included, and the limitations inherent to the choice of search words.
As stated, previous research on IQ impact has mostly focused on individuals, not organizations. However, organizations may be impacted several different ways, where researchers likely will use different terminology (e.g., organizational performance, process performance, organizational impact etc.). Thus, a heuristic approach of defining the search words was employed. Several search words synonymously with 'performance' were used in initial test searches. Some relevant articles were already identified, and new search words were added to ensure these articles were included in the results. The search words used in this study are presented in Table 1. The inclusion of several search words was done by purpose, expecting that the search would return too many articles. However, this strategy would increase the possibility of finding all relevant articles, knowing this would make the screening process more extensive.

Common databases used in IS reviews [34], i.e., ProQuest (all databases), IEEE Xplore and EBSCOhost were selected. Additionally, Scopus and ISI Web of Science were chosen to ensure multi-disciplinary. The databases were investigated to ensure indexing of IS journals, and all top-50 journals [1] were covered but one (MISQ Discovery). All searches were done in conjunction with "information quality" OR "data quality". The result is presented in Table 1 .

The initial search returned 2823 articles. Of these, 1260 duplicates were removed, fourteen were inaccessible, sixty-one non-English, twenty-nine too general (typically summaries of journals or conferences), and 1299 removed because of relevance.

Table 1. Search words and results

\begin{tabular}{|l|c|c|c|c|c|c|}
\hline Search word & ISI Web & ProQuest & Scopus & IEEE Xplore & Ebscohost & Total \\
\hline "change process*" & 2 & 2 & 14 & 0 & 4 & 22 \\
\hline "quality improvement*" & 130 & 76 & 454 & 27 & 421 & 1108 \\
\hline "process* performance*" & 2 & 2 & 28 & 0 & 10 & 42 \\
\hline "process* improve*" & 17 & 7 & 55 & 0 & 25 & 104 \\
\hline "process* impact*” & 1 & 1 & 5 & 0 & 21 & 28 \\
\hline "process* management" & 11 & 5 & 69 & 7 & 22 & 114 \\
\hline "organi* performanc*" & 20 & 5 & 39 & 0 & 42 & 106 \\
\hline "organi* improve*" & 0 & 0 & 3 & 0 & 2 & 5 \\
\hline "organi* impact*" & 11 & 6 & 25 & 0 & 20 & 62 \\
\hline "service* improve*" & 4 & 7 & 12 & 0 & 17 & 40 \\
\hline "service* performance*” & 7 & 4 & 22 & 0 & 9 & 42 \\
\hline "service* impact*” & 0 & 0 & 0 & 0 & 10 & 10 \\
\hline "operation* performance*" & 9 & 3 & 31 & 0 & 10 & 53 \\
\hline "operation* improve*" & 1 & 0 & 6 & 0 & 1 & 8 \\
\hline "operation* impact*" & 1 & 0 & 2 & 0 & 14 & 17 \\
\hline "total quality management" & 14 & 9 & 334 & 3 & 95 & 455 \\
\hline "tqm" & 5 & 7 & 22 & 0 & 8 & 42 \\
\hline "information quality management" & 15 & 14 & 108 & 15 & 39 & 191 \\
\hline "iqm" & 2 & 2 & 15 & 4 & 5 & 28 \\
\hline "health* improve* & 6 & 3 & 8 & 0 & 12 & 29 \\
\hline "adverse event*" & 51 & 44 & 65 & 0 & 111 & 271 \\
\hline
\end{tabular}


Again, this large number of non-relevant articles was expected and part of the strategy. These articles were judged non-relevant to this research based on screening of titles, abstracts, and full-text review when necessary. The following four criteria were used to assess whether an article was relevant or not: 1) the article must discuss the concept of IQ or DQ and impact on organizational factors (e.g., processes, services, operations, performance, improvement, etc.). 2) Articles were excluded when the objective was to investigate impact outside the focal organization (i.e., IQ impact on regional, national, and international aggregated systems). 3) Articles were excluded when the focal topic was IQ quality in clinical trials. 4) Articles were excluded when IQ impact was on data management itself.

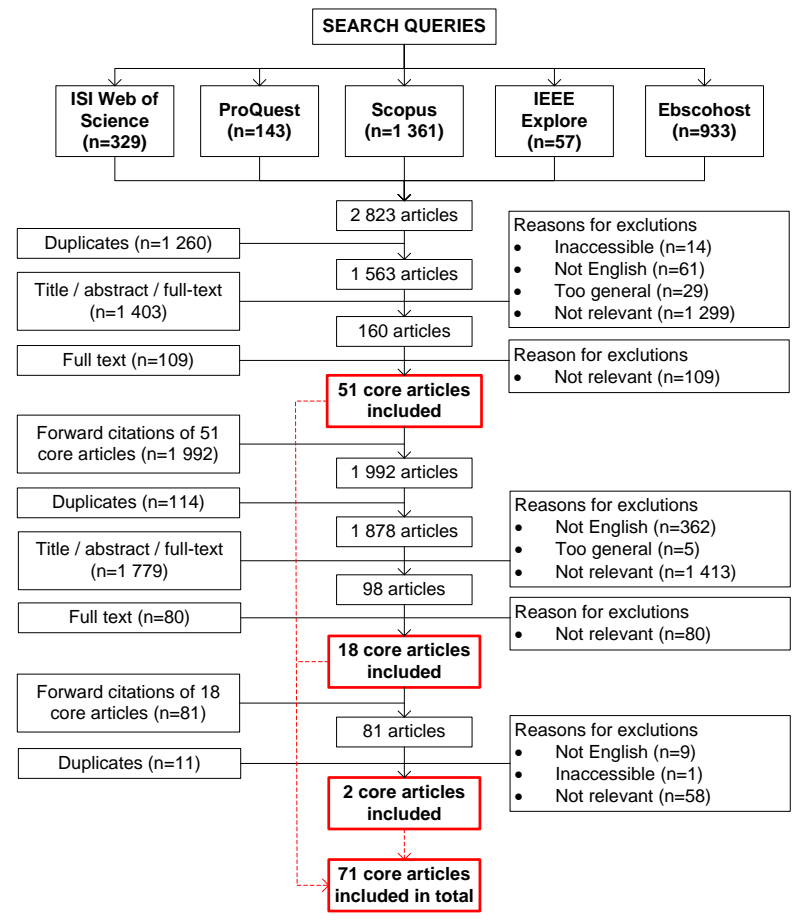

Figure 1. Data reduction procedure

160 articles remained after this process, which in turn were carefully assessed by full-text review. This led to further reduction, leaving fifty-one core articles left. A forward citation search of these fifty-one articles returned 1992 articles for further examination. The same procedure (described above) was conducted, adding eighteen new articles to the core collection. A second round of forward-research was performed on these eighteen articles, resulting in two more core articles (seventy-one in sum). A backward search of the first batch of core articles was intended, but this search returned 2321 articles. Thus, a full backward search was not feasible within the scope of this research. To partially address this limitation, all citations from the core articles used in this research were investigated and assessed, but none were found relevant to be included in the core collection. The data reduction procedure is illustrated in Figure 1.

There was not conducted any quality appraisal of the core articles. The reason for this is primarily based on the epistemological assumptions of critical realism, and also suggested in theory landscaping, where the review is exploratory and all new ideas, however unorthodox, are welcomed as long as they are supported by theoretical arguments [43].

The extracted data was analyzed in nVivo 10. The core articles addressed a myriad of research questions. In order of making sense, the articles were classified inductively by identifying all the dependent variables (what the articles tried to explain), and by carefully investigating the reasoning presented. Data was analyzed from different angles, including analysis of article metadata (year of publishing, research methods, and outlet target discipline). Central to the analysis was a concept-centric analysis [57]. The search ended May $22^{\text {nd }} 2016$.

\section{Findings}

\subsection{Review sample}

The seventy-one core articles in the core collection of the review included journal papers (53 articles), conference proceedings (17), and one unpublished work. The distribution of articles in domain-specific outlets is presented in Figure 2.

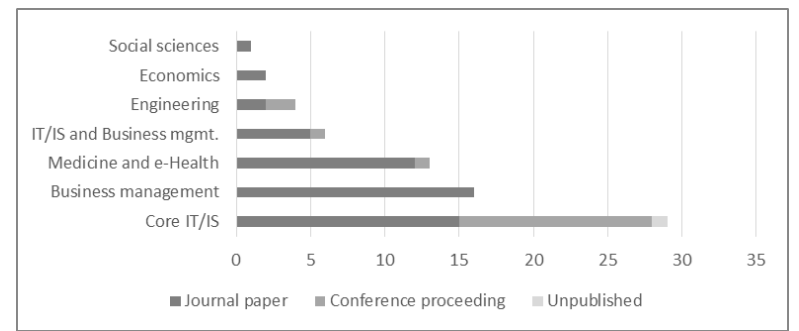

Figure 2. Outlet domain affiliation

In total, 50 percent of the articles were published in IT/IS journals or conferences, and 14 percent published in top-ranked journals or conferences. Ten articles where either published in journal outlets ranked as top100 IS journals [1], or presented in a top-ranked conference [34]. These outlets included Decision Support Systems, International Journal of Information Management, Journal of the Association for Information Systems, Journal of Management Information Systems, Journal of Strategic Information Systems, Information Technology \& Management, and 
proceedings of the Americas Conference on Information Systems (AMCIS). 52 percent of the identified articles were published after 2012, peaking in 2013. This strengthens the argument that IQ research was not concerned of organizational impact in the first two decades.

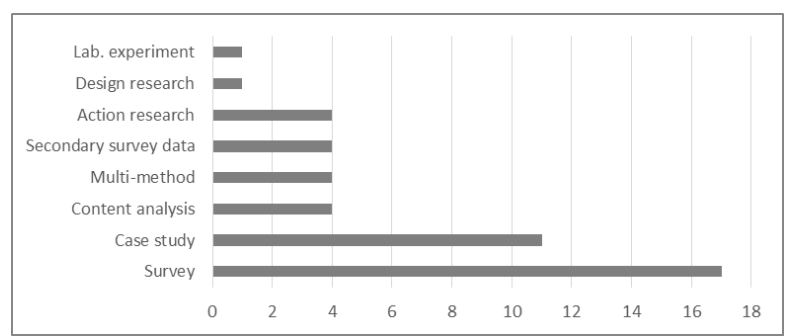

Figure 3. Research method

The majority of the research identified was empirical (46 articles), while the remaining was nonempirical / conceptual work (15) and literature reviews (10). The research methods of the empirical-based articles are summarized in Figure 3. Content analysis included extraction of clinical data from Electronic health records (EHR), while secondary survey data was reuse of survey data collected in previous studies or for governmental use.

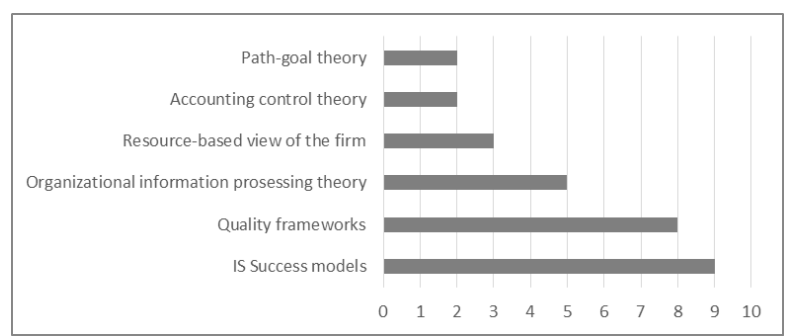

Figure 4. Frameworks and theories used

Several different theoretical perspectives or frameworks used in the core articles were identified. Some research used multiple frameworks or theories, while no frameworks/theories were identified in thirtythree instances. The frameworks or theories used in more than two articles are presented in Figure 4. IS success models and different quality frameworks were identified as most commonly used as theoretical references. IS success models included D\&M's first and second (revised) IS Success Model, and TAM, while quality frameworks included Total Quality Management (TQM), Six Sigma, Baylor Quality Practices, Total Data Quality Management (TDQM), Total Information Quality Management (TIQM), and Information Quality Management (IQM).

The topics that emerged from the analysis were related to how IQ impacted organizational performance, process/operational performance, process improvement, and decision-making. Some articles overlapped, making the classification of conceptualizations difficult. In these cases, articles were classified based on the main objective and contribution. Only a few articles were found to be investigating the role of IQ in a holistic manner, including all conceptualizations but process improvement [11]. The conceptualizations are presented below, and are summarized in Table 2 .

\subsection{Conceptualizations}

In studies discussing the role of IQ in organizational performance, performance was operationalized in 50 percent of the articles, however with different variables. The remaining articles operated with more diffuse definitions. Alenezi, Tarhini and Masa'deh [5] concluded that in spite of the vast amount of research on IQ, only a few studies offered insights in the relationship between IQ and organizational performance, and that the limited research tended to focus on private rather than public organizations. However, several authors claimed that IQ was the leading factor to improved performance of organizations, where the majority of articles within this conceptualization were empirical (see Figure 5).

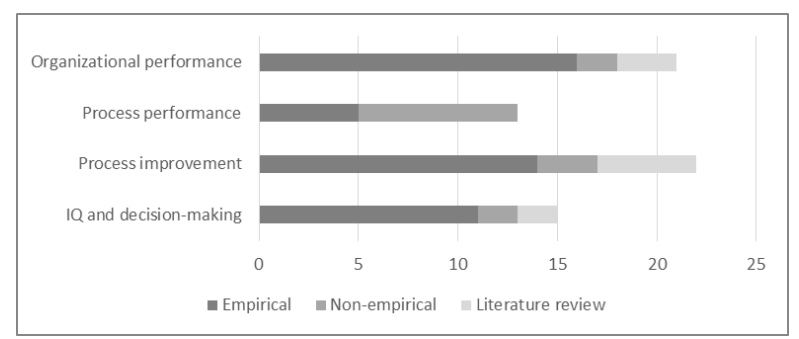

Figure 5. Research design

Analysis revealed IQ to be related to organizational performance in several ways. IQ was most often described in an indirect relation, meaning that IQ affected organizational performance through other variables. This research was underpinned by variants of TAM or IS success models, where IQ typically affected usefulness/use and user satisfaction which in turn impacted organizational performance $[10,15,31$, 46]. IQ was affecting organizational performance through several organizational factors, including user needs, service consolidation, communication, and human resources [6], customer satisfaction of IS [15], quality improvement [22], and management capabilities [50].

Another type of indirect relation considered IQ in a benefits perspective, where IQ was related to strategic benefits and institutional value, which in turn determined organizational performance [6]. 
IQ was also affecting organizational performance directly, both as a single factor (exclusively) or in conjunction with other variables (non-exclusively). In exclusive relations, dimensions of IQ were directly affecting different aspects of organizational performance, e.g., financial and marketing performance [7, 59]. In non-exclusive relations, IQ was typically clustered with system quality and service quality into technological factors, affecting in conjunction with organizational factors including top management support, user training, computer selfefficacy, and user experience [4] and quality improvement [e.g., 29].

Finally, IQ was mediating the relationship between organizational performance and IS system quality [27], inter-firm trust in inter-organizational relationships [37], and moderating the effect of high performance work systems (HPWS) on organizational performance [47].

Unlike the first conceptualization, the majority of research considering the role of IQ in process performance was non-empirical and considered IQ in a process perspective with direct impact on business processes [12] and emphasized the importance of modelling processes to be IQ-aware [e.g., 24, 42].

Further, IQ was affecting process performance directly and exclusively, e.g., by leading to errors and adverse events in healthcare processes [14], and that dimensions of IQ (traceability, believability, and reputation) were related to four dimensions of the surgery process in an operating theatre (operating time, cost of operation process, facility utilization, and length of waiting queue) [54].

Finally, one study proposed that IQ was both mediating and moderating the effect of IS on business operations [52].

Primarily empirical work was identified in conceptualization of how IQ impacted process improvement (including business process improvement, quality improvement, and operation improvement). This conceptualization is closely related to the next - IQ impact on decision-making - since decision-making is a central part of process improvement, and since the primary purpose of information systems is to provide quality information for decisions [46]. This conceptualization was the most atypical for several reasons; least studies supported by theoretical frameworks (only 30 percent), 40 percent published outside IS outlets, and the majority was concerning HISs (70 percent).

In most studies IQ was directly affecting improvement of healthcare processes, e.g., by attending to IQ for improving clinical handover processes [e.g., 26], and by enabling line managers to disseminate information to facilitate healthcare quality improvement projects [e.g., 25, 40].

Further, some articles focused on the role of IQ from a process perspective, e.g., how improvement of IQ is crucial to reduce disruptions of surgery [e.g., 2]. Identifying IQ flaws in BPM was perceived to be important for improving the medical hand-over processes [13].

However, several studies reported challenges in IQ in order to use routinely collected data for process improvement purposes. This was particularly discussed within the healthcare domain, with contradictory conclusions of its appropriateness [e.g., 35, 40]. One study reported that in spite of efforts of measuring performance in healthcare, data was not often used by line managers for improvement [25].

The role of IQ in decision-making was briefly articulated in the majority of articles, but only a few studies investigated this relation as a core topic. The majority of these studies were empirical contributions presented in IS journals. Within this conceptualization, several studies were concerned with IQ in performance management systems (like KPIs, balanced scorecards etc.), and decision-making based upon such systems.

Table 2. Framework of conceptualizations and relations

\begin{tabular}{|c|c|c|c|c|}
\hline IQ relation to $\quad \rightarrow$ & $\begin{array}{l}\text { Organizational } \\
\text { performance }\end{array}$ & Process performance & Process improvement & Decision-making \\
\hline $\begin{array}{l}\text { Direct relation, } \\
\text { exclusive }\end{array}$ & $\begin{array}{l}\text { - Financial impact } \\
\text { - Marketing impact }\end{array}$ & $\begin{array}{l}\text { - Adverse events } \\
\text { - Operating theater efficiency } \\
\text { and utilization }\end{array}$ & $\begin{array}{l}\text { - Clinical hand-over } \\
\text { - TQM impact } \\
\text { - Information dissemination } \\
\text { - Quality improvement projects } \\
\end{array}$ & $\begin{array}{l}\text { - Patient safety } \\
\text { - Health policy } \\
\text { - Quality of care }\end{array}$ \\
\hline $\begin{array}{l}\text { Direct relation, non- } \\
\text { exclusive }\end{array}$ & $\begin{array}{l}\text { - Technological factors } \\
\text { - Organizational factors }\end{array}$ & & & $\begin{array}{l}\text { - Human factors } \\
\text { - Organizational factors } \\
\text { - Technological factors } \\
\end{array}$ \\
\hline Moderator & - HPWS & - IS impact & & \\
\hline Mediator & $\begin{array}{l}\text { - IS system quality } \\
\text { - Inter-firm trust }\end{array}$ & - IS impact & & \\
\hline Indirect & $\begin{array}{l}\text { - IS usefulness } \\
\text { - IS use } \\
\text { - Organizational factors } \\
\text { - Benefits } \\
\end{array}$ & $\begin{array}{l}\text { - Satisfaction } \\
\text { - Efficiency } \\
\text { - Effectiveness }\end{array}$ & $\begin{array}{l}\text { - Feedback } \\
\text { - Indicator use }\end{array}$ & $\begin{array}{l}\text { - IS Quality } \\
\text { - Perceived usefulness } \\
\text { - Satisfaction } \\
\text { - Top mgmt. support } \\
\end{array}$ \\
\hline Process perspective & & $\begin{array}{l}\text { - IQ awareness } \\
\text { - IQ in BPM } \\
\end{array}$ & - IQ in BPM & \\
\hline
\end{tabular}


In this conceptualization, IQ was directly related to decision-making in healthcare; poor quality in healthcare datasets leads to adverse decision-making [21], impact on decision-making at national and regional levels (e.g., reported healthcare data for funding and policy making), and clinical decisions on patient level [e.g., 33, 58].

IQ was also directly affecting decision-making in conjunction with other factors, such as human and organizational factors (e.g., individual knowledge and competence, process knowledge, incentive systems, management support, employee involvement, decision process efficiency, task ambiguity [e.g., 51, 56]) and technological factors (e.g., IS capabilities, system quality [e.g., 9]).

Finally, IQ was indirectly related to decisionmaking through perceived usefulness and satisfaction of IS [3].

\section{Discussion}

The analysis revealed a complex and fragmented body of research on how IQ impacts organizational processes. There was no homogenous operationalization of the term 'organizational performance' identified within the first conceptualization. Though one could expect some patterns, it was not surprising to find differences because of the spectrum of contexts and diversity of information systems under scrutiny. More surprising was the absence of operationalization and lack of a clear definition of organizational performance in half of the articles. It is worth noticing that organizational performance was more clearly defined in articles suggesting direct relationship between IQ and organizational performance. However, Jaklič, Popovič and Coelho [31], stated that information acquired by decision-makers will have no real impact on performance unless it is actually put in use when decisions are being made. This is a reasonable argument and suggests that the direct-relation models represent a somewhat simplistic view of how IQ is related to performance. Despite this "black box" between IQ and organizational performance, the identified research is valuable, particularly in relation to the decision-making process. The common denominator of the remaining articles was that IQ affected organizational performance indirectly, by being antecedent, moderator, or mediator of technological and/or organizational factors affecting performance. In general, these research models were more complex in nature. The models give, to some extent, insights of elements situated between IQ and performance, but with less emphasis on how organizational performance is actually impacted (i.e., pushing the black box one step ahead).

In contrast to the first conceptualization, the research on the role of IQ in process management was dominated by non-empirical studies. This research ranged from suggestions of designing business processes and process governance to be IQ-aware, to defining more specific relationships between IQ dimensions and process performance. With a few exceptions, these studies were generally lacking a clear conceptualization of process performance and thus, not succeeding to provide a clear understanding of how IQ actually is influencing process performance.

Interestingly, the majority of studies, identified within the conceptualization of IQ impacting process improvement, was published outside IS research and without being informed by theoretical frameworks. The dependent variable 'process improvement', often referred to as quality improvement in healthcare, was more clearly defined within this conceptualization than the corresponding dependent variables in the two first conceptualizations. This is not surprising, since the identified articles discussing process improvement tend to be less abstract, and focusing on particular processes (e.g., reducing disruptions in surgery, improving medical handovers). With contradictory conclusions of the appropriateness of routinely collected health data in process improvement, this implicates the crucial role of IQ in process improvement; either as barrier or facilitator to quality improvement initiatives.

Decision-making was often mentioned in the conceptualizations of organizational performance, process performance, and quality improvement, but the role was vaguely described and not included in the research models. Performance management systems were often mentioned in research concerning IQ and decision-making, suggesting that use of these systems, and the act of decision-making itself, are situated inside the black box between IQ and its impact on organizations. Several authors called for more research on this relationship, and the need to identify factors operating in conjunction with IQ in decision-making in order to achieve improved performance [e.g., 29].

The D\&M IS success model and TAM were only applied as theoretical frameworks in twelve of the studies included in this research. However, a vast amount of articles using such models were identified, but discarded as non-relevant for this study, due to their focus on improving IQ, without paying attention to the organizational impacts of this improvement. One could argue that the main focus of IQ research until now has been on defining, measuring, and managing information in order to achieve excellence in IQ. This assumption is supported by Neely and Cook [41], and confirmed in this study by identifying the moderately 
increasing research contributions, peaking in 2013. Thus, it might be timely to suggest a shift in focus, bearing in mind that "quality information is of little value to firms if it has not been used in firm's business processes" [31]. Similarly, performance information was not used in decision-making and quality improvement in healthcare [25]. This leads us to a curious paradox, particularly in healthcare: the majority of IQ research is, on the one hand, concerned with achieving excellence in IQ, whereas on the other hand, existing information is not utilized in process governance and process improvement. This concern is nicely expressed by Ginsburg in a healthcare outlet thirteen years ago, yet still equally relevant; "Admittedly, the performance and improvement literatures would be considered "new" relative to most work in the behavioral and organization sciences; it is therefore critical that researchers look to knowledge that exists in other fields as we try to understand how to truly use performance data for bringing about improvements in health care delivery" [25]. Bearing the current research focus of IQ in mind, it is important to realize this implication; IQ should not be perceived as an end itself, but rather as a means to achieve favorable organizational ends.

\section{Implications and future research agenda}

Interdisciplinary knowledge creation is important for IQ research relevancy for organizations in general and healthcare in particular, in order to facilitate process governance, identifying opportunities for improvement, and guiding the improvement towards success. For researchers situated in the field of IS, it is thus important to investigate IQ more broadly and with different theoretical lenses, until a more common understanding of how IQ is impacting organizations is reached. By this, it is suggested to be cautious when reviewing existing knowledge; as documented in this paper, the existing body of knowledge of IQ research is multi-disciplinary, and not only found in top-ranked journals.

Overall, the analysis of articles identified reveals several opportunities for future research: First and foremost, research should investigate in-depth how IQ is actually impacting organizations. The dependent variables 'organizational performance' and 'process performance' seem to be only vaguely described, thus diminishing the practical usefulness of the research. This is consistent with several authors and expressed in recent calls for research [e.g., 7]. Second, the relationship between IQ and process improvement is scarce in general, and within the IS discipline in particular. Since this area is under-investigated, also supported by a recent call for research [45], and the few existing studies lack theoretical underpinnings, exploratory in-depth research is needed for better understanding of the problem domain. Future research should investigate how IQ may facilitate process governance, improvement processes, and investigate how decision-making and performance management systems are related to process improvement. Third, research on how all the identified conceptualizations are concerted is recommended, in order to understand the end-to-end impacts of IQ in organizations. The proposed framework (Table 2) may serve as a starting point for such research, where findings could be tested empirically in order to refine the framework in a healthcare context. Further, the absence of findings in the framework provides research opportunities; e.g., no research was found on IQ as mediating or moderating effects on process improvement or decision-making.

\section{Conclusion}

This study has reviewed multi-disciplinary research on how information quality impacts organizations. The current state of this research is presented, revealing fragmented streams where contributions within the IS research community represented only one half of the current body of knowledge. Analysis indicated a tendency of the current research to fit into one of four conceptualizations of organizational impact of IQ; IQ and organizational performance, IQ and process performance, IQ and process improvement, and IQ in decision-making. The conceptualizations, and their relations to IQ, are presented in a framework. In an era of ever-increasing amount of health data, it is important to understand its implications on healthcare processes, thus this paper suggests a shift of focus in the current IQ research from defining, assessing, and aiming for IQ excellence, to understanding the impact towards better and safer health services.

\section{References}

[1] http://aisnet.org/?JournalRankings, accessed Feb. 22nd, 2016 .

[2] Al-Hakim, L., "Surgical Disruption: Information Quality Perspective", International Journal of Information Quality, 2(2), 2008, pp. 192-204.

[3] Al-Mamary, Y.H., Shamsuddin, A., and Aziati, N., "The Impact of Management Information Systems Adoption in Managerial Decision Making: A Review", Journal of Management Information Systems, 8(4), 2013, pp. 10-17.

[4] Al-Mamary, Y.H., Shamsuddin, A., and Aziati, N., "The Pilot Test Study of Relationship Between Management Information Systems Success Factors and Organizational Performance at Sabafon Company in Yemen", International 
Journal of U-\& E-Service, Science \& Technology, 8(2), 2015, pp. 337-346.

[5] Alenezi, H., Tarhini, A., and Masa'deh, R., "Investigating the Strategic Relationship between Information Quality and e-Government Benefits: A Literature Review", International Review of Social Sciences and Humanities, 9(1), 2015, pp. $33-50$

[6] Alenezi, H., Tarhini, A., and Sharma, S.K., "Development of Quantitative Model to Investigate the Strategic Relationship Between Information Quality and eGovernment Benefits", Transforming Government: People, Process and Policy, 9(3), 2015, pp. 324-351.

[7] Argyropoulou, M., Reid, I., Wilkins, P., and Loannou, G., "Information Quality, Reporting and Organisational Performance", 22ND EurOMA Conference, 2015

[8] Batini, C., Cappiello, C., Chiara, F., and Maurino, A., "Methodologies for Data Quality Assessment and Improvement", ACM Computing Surveys, 41(3), 2009, pp. 16:11-16:52.

[9] Bento, A., and Bento, R., "Factors Affecting the Outcomes of Performance Management Systems", 12th Americas Conference on Information Systems, AMCIS, 2006, pp. 50-58.

[10] Bento, A.L., Bento, R., and Ferreira White, L., "Strategic Performance Management Systems: Impact on Business Results", Journal of Computer Information Systems, 54(3), 2014, pp. 25-33.

[11] Borek, A., Helfert, M., Ge, M., and Parlikad, A.K., "IS/IT Resources and Business Value: Operationalization of an Information Oriented Framework", 13th International Conference on Enterprise Information Systems, ICEIS, 2012, pp. 420-434.

[12] Borek, A., Parlikad, A.K., Woodall, P., and Tomasella, M., "A Risk Based Model for Quantifying the Impact of Information Quality", Computers in Industry, 65(2), 2014, pp. 354-366.

[13] Chircu, A.M., Gogan, J.L., Boss, S.R., and Baxter, R., "Medication Errors, Handoff Processes and Information Quality: A Community Hospital Case Study", Business Process Management Journal, 19(2), 2013, pp. 201-216.

[14] Clark, J.S., Delgado, V.A., Demorsky, S., Dunagan, E.A., and Eichelmann, T.A., "Assessing and improving EHR data quality (updated)", Journal of the American Health Information Management Association, 84(3), 2013, pp. 4853.

[15] Daunoriene, A., and Zekeviciene, A., "A Reference Model of Public Institutions' Quality Practices, Citizens' Satisfaction and Performance Quality", Engineering Economics, 26(4), 2015, pp. 422-430.

[16] Davis, F.D., A Technology Acceptance Model for Empirically Testing New End-User Information Systems: Theory and Results, Massachusetts Institute of Technology, 1986.

[17] DeLone, W., and McLean, E., "The DeLone and McLean Model of Information Systems Success: A Ten-Year Update", Journal of Management Information Systems, 19(4), 2003, pp. 9-30.
[18] DeLone, W., and McLean, E., "Information Systems Success: The Quest for the Dependent Variable", Information Systems Research, 3(1), 1992, pp. 60-95.

[19] Dixon-Woods, M., McNicol, S., and Martin, G., "Ten Challenges in Improving Quality in Healthcare: Lessons from the Health Foundation's Programme Evaluations and Relevant Literature", BMJ Quality \& Safety, 21(10), 2012, pp. 876-884.

[20] Evans, J.R., Foster jr., S.T., and Linderman, K., "A Content Analysis of Research in Quality Management and a Proposed Agenda for Future Research", The Quality Management Journal, 21(2), 2014, pp. 17-44.

[21] Foshay, N., and Kuziemsky, C., "Towards an Implementation Framework for Business Intelligence in Healthcare", International Journal of Information Management, 34(1), 2014, pp. 20-27.

[22] Fotopoulos, C.V., and Psomas, E.L., "The Structural Relationships between TQM Factors and Organizational Performance", TQM Journal, 22(5), 2010, pp. 539-552.

[23] Ge, M., and Helfert, M., "A Review of Information Quality Research - Develop a Research Agdenda", 12th International Conference on Information Quality, 2007

[24] Gharib, M., and Giorgini, P., "Modeling and Reasoning about Information Quality Requirements in Business Processes": Enterprise, Business-Process and Information Systems Modeling, Springer, 2015, pp. 231-245.

[25] Ginsburg, L.S., "Factors that Influence Line Managers' Perceptions of Hospital Performance Data", Health Services Research, 38(1), 2003, pp. 261-286.

[26] Gogan, J.L., Baxter, R.J., Boss, S.R., and Chircu, A.M., "Handoff Processes, Information Quality and Patient Safety: A Trans-Disciplinary Literature Review", Business Process Management Journal, 19(1), 2013, pp. 70-94.

[27] Gorla, N., Somers, T.M., and Wong, B., "Organizational Impact of System Quality, Information Quality, and Service Quality", Journal of Strategic Information Systems, 19(3), 2010, pp. 207-228.

[28] Gullkvist, B., "Drivers of Change in Management Accounting Practices in an ERP Environment", International Journal of Economic Sciences and Applied Research, 6(2), 2013, pp. 149-174.

[29] Harris, M.L., McDowell, W.C., and Gibson, S.G., "Strategic Relationships in a Small Business Context: The Impact of Information Quality and Continuous Quality Improvement", New England Journal of Entrepreneurship, 14(2), 2011, pp. 1-9.

[30] Hermon, R., and Williams, P.A.H., "Big Data in Healthcare: What is it Used for?", Australian eHealth Informatics and Security Conference, 2014, pp. 40-49.

[31] Jaklič, J., Popovič, A., and Coelho, P.S., "The Impact of Quality Information Provided by Business Intelligence Systems on the Use of Information in Business Processes", International Conference on Enterprise Information Systems, CENTERIS, 2011, pp. 158-167.

[32] Karr, A.F., Sanil, A.P., and Banks, D.L., "Data Quality: A Statistical Perspective", Statistical Methodology, 3(2006, pp. 137-173. 
[33] Kerr, K.A., Norris, T., and Stockdale, R., "The Strategic Management of Data Quality in Healthcare", Health Informatics Journal, 14(4), 2008, pp. 259-266.

[34] Levy, Y., and Ellis, T.J., "A Systems Approach to Conduct an Effective Literature Review in Support of Information Systems Research", Informing Science Journal, 9(9), 2006, pp. 181-212.

[35] Liaw, S.-T., Taggart, J., Yu, H., and de Lusignan, S., "Data Extraction from Electronic Health Records - Existing Tools May be Unreliable and Potentially Unsafe", Australian Family Physician, 42(11), 2013, pp. 820-823.

[36] Liaw, S.T., Rahimi, A., Ray, P., Taggart, J., Dennis, S., de Lusignan, S., Jalaludin, B., Yeo, A.E.T., and TalaeiKhoei, A., "Towards an Ontology for Data Quality in Integrated Chronic Disease Management: A Realist Review of the Literature", International Journal of Medical Informatics, 82(1), 2013, pp. 10-24.

[37] McDowell, W.C., and Karriker, J.H., "The Role of Information Quality as a Mediator of the Trust-Performance Relationship", Journal of Business Issues, 2009(1), 2009, pp. 33-45.

[38] Mettler, T., Rohner, P., and Baacke, L., "Improving Data Quality of Health Information Systems: A Holistic Design-Oriented Approach", European Conference on Information Systems, 2008

[39] Mingers, J., Mutch, A., and Willcocks, L., "Critical Realism in Information Systems Research", MIS Quarterly, 37(3), 2013, pp. 795-802.

[40] Needham, D.M., Sinopoli, D.J., Dinglas, V.D., Berenholtz, S.M., Korupolu, R., Watson, S.R., Lubomski, L., Goeschel, C., and Pronovost, P.J., "Improving Data Quality Control in Quality Improvement Projects", International Journal for Quality in Health Care, 21(2), 2009, pp. 145-150.

[41] Neely, M.P., and Cook, J.S., "Fifteen Years of Data and Information Quality Literature: Developing a Research Agenda for Accounting", Journal of Information Systems, 25(1), 2011, pp. 79-108.

[42] Ofner, M.H., Otto, B., and Österle, H., "Integrating a Data Quality Perspective into Business Process Management", Business Process Management Journal, 18(6), 2012, pp. 1036-1067.

[43] Okoli, C., "A Critical Realist Guide to Developing Theory with Systematic Literature Reviews", John Molson School of Business, Concordia University Montreal, Canada, Available at SSRN 2115818, 2012

[44] Okoli, C., "A Guide to Conducting a Standalone Systematic Literature Review", Communications of the Association for Information Systems, 37(43), 2015, pp. 879910.

[45] Panahy, P.H.S., Sidi, F., Affendey, L.S., and Jabar, M.A., "The Impact of Data Quality Dimensions on Business Process Improvement", 4th World Congress on Information and Communication Technologies, WICT, 2014, pp. 70-73.

[46] Petter, S., DeLone, W., and McLean, E.R., "Information Systems Success: The Quest for the Independent Variables", Journal of Management Information Systems, 29(4), 2013, pp. 7-62.
[47] Preuss, G.A., "High Performance Work Systems and Organizational Outcomes: The Mediating Role of Information Quality", Industrial \& Labor Relations Review, 56(4), 2003, pp. 590-605.

[48] Price, R., Shanks, G., and Neiger, D., "Developing a Measurement Instrument for Subjective Aspects of Information Quality", Communications of the Association for Information Systems, 22(1), 2008, pp. 1-29.

[49] Sagawa, J., and Nagano, M., "Integration, Uncertainty, Information Quality, and Performance: A Review of Empirical Research", International Journal of Advanced Manufacturing Technology, 79(1-4), 2015, pp. 299-306.

[50] Sánchez-Rodríguez, C., and Martínez-Lorente, A.R., "Effect of IT and Quality Management on Performance", Industrial Management and Data Systems, 111(6), 2011, pp. 830-848.

[51] Shankaranarayanan, G., Even, A., and Watts, S., "The role of process metadata and data quality perceptions in decision making: an empirical framework and investigation", Journal of Information Technology Management, 17(1), 2006, pp. 50-67.

[52] Sheng, Y.P., "Exploring the Mediating and Moderating Effects of Information Quality on Firms' Endeavor on Information Systems", Eighth International Conference on Information Quality, ICIQ, 2003, pp. 344-353.

[53] Stvilia, B., Twidale, M.B., Smith, L.C., and Gasser, L., "Information Quality Work Organization in Wikipedia", Journal of the American Society for Information Science and Technology, 59(6), 2008, pp. 983-1001.

[54] Su, Y., and Shen, N., "Modeling the Effects of Information Quality on Process Performance in Operating Rooms", 12th UKSim International Conference on Modelling and Simulation, UKSim, 2010, pp. 175-178.

[55] Wang, R.Y., and Strong, D.M., "Beyond Accuracy: What Data Quality Means to Data Consumers", Journal of Management Information Systems, 12(4), 1996, pp. 5-33.

[56] Watts, S., Shankaranarayanan, G., and Even, A., "Data quality assessment in context: A cognitive perspective", Decision Support Systems, 48(1), 2009, pp. 202-211.

[57] Webster, J., and Watson, R.T., "Analyzing the Past to Prepare for the Future: Writing a Literature Review", MIS Quarterly, 26(2), 2002, pp. xiii-xxiii.

[58] Welzer, T., Brumen, B., Golob, I., Sanchez, J.L., and Družovec, M., "Diagnostic Process from the Data Quality Point of View", Journal of Medical Systems, 29(1), 2005, pp. 59-63.

[59] Xiang, J., Lee, S., and Kim, J., "Data Quality and Firm Performance: Empirical Evidence from the Korean Financial Industry", Information Technology \& Management, 14(1), 2013, pp. 59-65. 